\title{
Nietzsche y el pathos de la verdad
}

\section{Greta RIVARA KAMAJI \\ Universidad Nacional Autónoma de México}

\begin{abstract}
A lo largo del siglo Xx, el lenguaje se convirtió en uno de los ejes centrales de la filosofía. El siglo pasado fue el siglo de Heidegger, por su célebre desplazamiento del problema de la existencia al problema del lenguaje; de Gadamer, por su monumental formulación de la hermenéutica filosófica, y de Ricœur, por su vía larga. Sin embargo, todo esto no constituye solamente un acierto del siglo XX, sino el trabajo de recepción de una herencia que, considero, es la herencia de Friedrich Nietzsche. En este artículo examino cómo, si Nietzsche pudo poner en crisis esa Razón que creía tener el control total de sí misma y de lo real, fue porque introdujo el problema de la verdad en el terreno del lenguaje y del arte. Al ubicar la verdad en el terreno del lenguaje y, por tanto, de la interpretación y la perspectiva, lo que Nietzsche reclamó fue la necesidad de construir una racionalidad cruzada por la historicidad y la finitud, una concepción de la vida como donación de sentido. Así, lo que Nietzsche develó, fue el poder ontológico del lenguaje.
\end{abstract}

PALABRAS ClAVE: Friedrich Nietzsche, ontología, lenguaje, ficción, verdad.

Throughout the twentieth century, language became a central topic for Philosophy. The past century was that of Heidegger, thanks to his famous shift of the problem of existence to the problem of language; of Gadamer, for his monumental formulation of philosophical hermeneutics; and of Ricœur, for his long way. However, all of this does not constitute solely an insight of twentieth century thinkers, but rather the reception of an inheritance, I believe, is the legacy of Friedrich Nietzsche. In this article I examine the way Nietzsche was able to put in crisis, by introducing the problem of truth in the field of language, that Reason which believed to be in full possession of itself and of what is real. By placing the truth in the field of language and, therefore, interpretation and perspective, what Nietzsche claimed was the need to build a rationality infused in historicity and finitude, a conception of life as a donation of meaning. In so doing, what Nietzsche unveiled was the ontological power of language.

KEY WORDS: Friedrich Nietzsche, ontology, language, fiction, truth.

Desde muchas perspectivas podríamos afirmar que, para la historia de la filosofía, el siglo XX fue el siglo del lenguaje. En la época anterior fue el tema del conocimiento el que dominó las preocupaciones del pensamiento filosófico, hasta tal punto que en la 
filosofía moderna casi cualquier problema era referido al tema del conocimiento y de su validez. Sin embargo, a lo largo del siglo XX, el lenguaje se convirtió en uno de los ejes centrales de la filosofía, si no es que en el centro en torno al cual comenzaron a gravitar otros problemas.

El siglo XX llevó a cabo críticas decisivas a la preeminencia que el pensamiento moderno había otorgado al conocimiento y buscó resolver las enormes aporías que aquél nos había legado. Así, las grandes preocupaciones de las filosofías modernas, desde el renacimiento cartesiano hasta la trascendentalidad husserliana, pasando por el giro copernicano de Kant y el espíritu hegeliano, observarían una profunda transformación de todos sus afanes. El conocimiento y su validez quedarían subsumidos a un ámbito más amplio, más fundamental: el lenguaje. Éste aparecería en el siglo XX como una llave maestra que abriría todas las puertas, como una vía para reformular, reposicionar y darle otro tratamiento a nuevos y viejos temas. Ahora, la filosofía ya no intentaría alcanzar el conocimiento, sino pensar desde el lenguaje; ya no haría epistemología, sino ontología.

Fue así que la obsesión por la verdad, que había caracterizado a las filosofías de los siglos precedentes, se inscribió en el siglo XX como un tema más, situado en el gran problema del lenguaje. La verdad ya no inquieta sino en tanto que pertenece al lenguaje, en tanto que solamente desde el lenguaje puede ser tratada. Parecería, entonces, que a partir del siglo XX la pregunta por la verdad sólo es legítima si se plantea dentro de la pregunta por el lenguaje o, mejor dicho, es la pregunta por el lenguaje la que nos autoriza a preguntar por la verdad. De esta forma, el vínculo entre el problema del lenguaje y el problema de la verdad quedaría establecido como uno de los hallazgos básicos de las filosofías del siglo XX.

Visto de esta manera, el siglo pasado fue el siglo de Martin Heidegger, de Hans-Georg Gadamer y de Paul Ricœur. Del primero, por su célebre desplazamiento del problema de la existencia al problema del lenguaje y la subsecuente ontologización del lenguaje que llevó a cabo a lo largo de su obra. ${ }^{1}$ De Gadamer, por su monumental formulación de la hermenéutica filosófica, cuyo punto de partida y sustento permanente es una ontología del lenguaje. Y de Ricœur, por su vía larga que, asumiendo una concepción ontológica del lenguaje como punto de partida, critica, a su vez, a los dos pensadores anteriores, planteando la necesidad de transitar de El Lenguaje hacia los lenguajes.

Resulta indudable, pues, que la identificación heideggeriana entre ser y lenguaje marcara una impronta fundamental sobre la forma en que el siglo Xx trataría el problema. Es en ese horizonte en el que Gadamer inscribiría el tema de la historicidad de la conciencia y el gran tema de la tradición. Y también en ese horizonte Ricœur plantearía su

\footnotetext{
${ }^{1}$ Desde mi perspectiva, Heidegger comienza con este planteamiento desde Ser y tiempo. La formulación del círculo hermenéutico es paradigmática en ese sentido. Considero que esta formulación está presente y es el punto de partida de los planteamientos sobre el lenguaje establecidos en la "Carta sobre el humanismo". Lo mismo podríamos decir incluso de su hermenéutica de la facticidad. Cf. M. Heidegger. Ser y tiempo; "Carta sobre el humanismo"; y Ontología: hermenéutica de la facticidad.
} 
pregunta por la metaforicidad del lenguaje y elaboraría su propuesta de la identidad narrativa, ${ }^{2}$ lanzándose a formular una concepción distinta de la verdad, un modelo de racionalidad construido desde la reflexión sobre la obra de arte literaria pensada a partir de una formulación sobre el lenguaje. ${ }^{3}$

Pero hay que advertir que todo esto no constituye solamente un acierto del siglo $\mathrm{XX}$, sino el trabajo de recepción de una herencia que llegó, sobre todo, a la segunda mitad del siglo. Se trata, considero, de la herencia de Friedrich Nietzsche. No es gratuito que en las últimas décadas hayamos asistido a una recuperación del Nietzsche que se ocupó del lenguaje. La hermenéutica y el giro lingüístico hicieron inevitable esta relectura, esta recuperación de tal dimensión de su obra. Cierto que esta herencia no se pudo ver claramente hasta que la hermenéutica y sus efectos cobraron un papel fundamental en la filosofía. Durante mucho tiempo no se leyó a Nietzsche en esa clave, y ni siquiera sus grandes lectores se concentraron necesariamente en su acercamiento al lenguaje.

Si hiciéramos una "historia efectual" sobre las interpretaciones fundamentales de la obra de Nietzsche, advertiríamos que existen grupos de lecturas que, en momentos determinados, se concentraron en aspectos precisos y los privilegiaron según ciertas necesidades: las de la propia filosofía, las de la época, etcétera. Conocemos de sobra los momentos en los que se ha priorizado al Nietzsche de la crítica a la razón y a la moral. Durante la primera mitad del siglo, en la Europa de entreguerras, el enfoque principal de las lecturas nietzscheanas tenía que ver con la crítica a la cultura, con la presencia del nihilismo que conectaba con el colapso del mundo europeo. En la segunda mitad del siglo XX, en cambio, cuando el tema del nihilismo dejó de tener tanta fuerza existencial, pudo ocurrir la emergencia de otros temas y la reconsideración de su relevancia. Las primeras lecturas precisaban leer a aquel Nietzsche junto con el cual era posible señalar la decadencia de Occidente, la caída de sus grandes proyectos, de sus grandes concepciones e ídolos. Esto fue así al menos en las primeras décadas del siglo XX. Incluso después, cuando Heidegger realizó su monumental lectura de Nietzsche, no puso el acento principal en las preocupaciones nietzscheanas por reformular el problema del lenguaje y, junto con éste, el de la verdad. Sin embargo, la presencia de Nietzsche en muchos de los grandes presupuestos de las filosofías del siglo Xx permitió una hermeneutización de ese pensamiento nietzscheano que, en última instancia, fijó las bases fundamentales para los desarrollos alcanzados por Heidegger, Gadamer o Ricœur, entre otros. Podríamos considerar las lecturas que se hicieron en la segunda mitad del siglo, que veían a Nietzsche en clave "lingüística" y, con ello, rescataban esa dimensión de su pensamiento que tanta atención merece, como un efecto de sentido del siglo XX.

Aunado a lo anterior, las grandes reflexiones y aportaciones que Heidegger y Gadamer hicieron en torno al tema de la obra de arte, así como sus intentos por recuperar

\footnotetext{
${ }^{2}$ Baste ver, como ejemplo, el texto de Paul Ricoeur "La identidad narrativa" en Historia y narratividad.

${ }^{3}$ Un gran ejemplo de estas formulaciones se encuentra en La metáfora viva de Paul Ricoeur.
} 
una concepción de la verdad desde esa reflexión, ${ }^{4}$ hicieron posible una relectura de aquel Nietzsche para el cual los vínculos ontológicos entre verdad, conocimiento y lenguaje removieron los cimientos sobre los cuales se había estructurado la tradición filosófica metafísica. Algo similar sucedió con el extenso y profundo trabajo de Ricœur sobre la metáfora y la metaforicidad del lenguaje, que hizo voltear todavía más la atención hacia el Nietzsche que inscribió el tema de la metáfora como una de las preguntas centrales que es necesario formular al preguntar por el lenguaje.

Así, un Nietzsche diferente comenzó a aflorar. La hermenéutica filosófica y su lugar fundamental en la filosofía - y en otras áreas del saber-comenzó a aportar elementos que nos permitirían radicalizar la importancia del Nietzsche que realizó las grandes formulaciones sobre la historicidad del ser, de la verdad, del lenguaje, de la conciencia. El siglo XX en sus últimas décadas necesitaba revisar estos temas, pues sobre ellos parecía urgente que se levantaran los cimientos de las filosofías presentes y de las filosofías por venir, aquellas que ya no deseaban estar más allá de los tiempos y sus avatares. Y, curiosamente, sería Nietzsche, un pensador del siglo XIX, el que terminaría colaborando enormemente para que la filosofía de las últimas décadas del siglo XX se posicionara, finalmente, a la altura de las circunstancias, a la altura de sus circunstancias.

Establecido entonces este panorama, revisaré en lo que sigue algunas de aquellas aportaciones del pensamiento de Nietzsche que no sólo son de enorme relevancia para entender el desarrollo de la filosofía de la segunda mitad del siglo Xx, sino que marcaron, de alguna manera, su agenda. Me concentraré especialmente en algunos aspectos del vínculo entre el lenguaje y la verdad que planteó Nietzsche y que, insisto, fue de enormes consecuencias para las filosofías del siglo que recién terminó, pero que no deja de seguir naciendo en el presente.

En "Sobre el pathos de la verdad”, Nietzsche se pregunta: “¿es la gloria realmente sólo el más delicioso bocado de nuestro amor propio?"(19). Para Nietzsche, el anhelo de gloria nos ha acompañado constantemente. Por momentos, dice, el ser humano se ha sentido irradiado por algo poderoso; desde esa irradiación ha sentido que ilumina el mundo y quiere imprimir a esa sensación de gloria el carácter de posteridad. En esos momentos el ser humano se siente inmortal, siente que ha conquistado el ineluctable movimiento, la transitoriedad de lo real. Y éste sería su triunfo sobre la realidad, pues al parecer nuestra ansia de gloria nos ha hecho mirar con horror el perpetuo movimiento de las cosas, que no es sino el signo máximo de nuestra propia finitud.

Los intentos por satisfacer ese anhelo de gloria y por dejar constancia de su presencia llevan al ser humano a desear que esos instantes de luminosidad tengan siempre herederos. Nos queremos para siempre, siempre presentes, y en esto, al parecer, hemos encontrado el sentido que da fundamento a la cultura: "La terrible batalla de la cultura se enciende por la pretensión de que lo grande debe ser eterno; pues todo lo otro [...] lo acostumbrado, lo pequeño, lo vil, llena cada rincón del mundo [...] se

\footnotetext{
${ }^{4}$ En el caso de Gadamer, recordemos que Verdad y método arranca desde su primera parte precisamente con esta reflexión. $C f$. H.-G. Gadamer, "Fundamentos de una hermenéutica filosófica", en Verdad y método.
} 
arroja obstruyendo [...] el camino en el que lo grande tiene que proseguir hacia la inmortalidad" (31).

Entre los seres humanos, nos dice Nietzsche, los filósofos parecen ser los más motivados por aquel anhelo, puesto que son ellos quienes han mostrado la mayor hostilidad hacia lo efímero y lo fugaz. Son ellos quienes han creído que pueden poseer de las cosas su permanencia, y a esa posesión le han llamado verdad. Los filósofos creen que el mundo necesita la verdad y que la necesita eterna, como eternos quieren ser ellos y sus conocimientos. Por eso, nos enseña Nietzsche, al inventar el conocimiento, inventamos también el instante más arrogante de nuestra historia.

Pero con esa invención, sin saberlo, también nos condenamos, porque al ser humano "la verdad lo impulsaría hacia la desesperación y la destrucción, la verdad de estar eternamente condenado a la falsedad” (38). ¿Cómo evalúa Nietzsche tal destrucción? En primer lugar, haciendo una crítica a la concepción de la verdad en la tradición filosófica y, en segundo, intentando construir otra concepción de la verdad. La crítica nietzscheana se dirige por lo tanto a los sistemas racionales, que suponen que la verdad es algo inamovible, un en-sí que se da a espaldas de la cambiante realidad. La verdad se contrapone, en dichos sistemas, a otra realidad que niega y devalúa: la realidad de la efímera y cambiante vida. En nombre de la verdad, pues, la filosofía ha negado la vida.

Lo que Nietzsche critica es el carácter dogmático de la verdad, esa necesidad de creer que la verdad está ahí, pura, lista para ser descubierta por todo sistema de racionalidad. Ahora bien, esto no quiere decir que Nietzsche haya renunciado a hablar de la verdad, de las verdades. Antes bien, Nietzsche lleva la verdad a otro terreno, aquel que cuestiona lo incuestionable, lo que se pretende absoluto. Este terreno es el de la vida, la vida que está por encima del conocimiento y la verdad. Este terreno es, por lo tanto, el del instinto, el del impulso de ilusión sobre el cual puede construirse todo conocimiento y toda la verdad. Y este terreno es también el de la historicidad y la temporalidad, ineluctable marca de toda verdad, de todo conocimiento. Se trata de un terreno en el que conocimiento y vida no están separados, en el que la afirmación de la vida no es la negación del conocimiento.

La sustitución de la vida por el concepto marcó la orientación con que la tradición racionalista delineó sus nociones de verdad, de realidad, de conocimiento. El metafísico suponía que su mundo conceptual era El Mundo. Por eso, vimos en el conocimiento racional nuestra eternidad, mas este conocimiento nunca bastó y por ello se tornó destrucción. No obstante, otras formas del conocimiento son posibles. Entre todas ellas, el arte parece ser la forma más poderosa, pues, sin saberlo, no destruye la vida, sino que la crea. ${ }^{5}$ La ilusión del artista (sobre todo trágico) busca acompañar los movimientos de la vida, transfigurándola perpetuamente. El artista no encuentra verdades inamovibles, sino siempre nacientes, siempre en gestación, acompasadas justamente con la vida.

\footnotetext{
${ }^{5}$ Recordemos que filosofía y arte serían para Nietzsche dos modos de crear ficciones, pero la ficción del arte acompaña más de cerca a la vida que las ficciones de la filosofía.
} 
Como sabemos, una de las herramientas críticas que Nietzsche construyó para llevar a cabo su crítica de la verdad en términos metafísicos fue la genealogía. Ésta es una estrategia de interpretación, estrategia desenmascaradora que anuncia que detrás de todos nuestros juicios de valor, de conocimiento, hay motivaciones, motivaciones por las que aquéllos operan, actúan. Estas motivaciones no son otra cosa que voluntad de poder.

En Sobre verdad y mentira en sentido extramoral, Nietzsche ubica el tema de la verdad en el terreno de la voluntad. Nuestro autor señala que es debido a nuestra voluntad de verdad que olvidamos que toda verdad no es sino una proyección de nuestra voluntad, de la necesidad imperiosa de que esa voluntad se muestre y se realice. Para Nietzsche, estamos sobrecogidos por un impulso de verdad que no es sino la necesidad misma de regular nuestro trato con la realidad. Y esa necesidad nos hace mentir, mentimos para poder vivir. Mentir para vivir es una estructura de la vida. El problema aparece cuando esto se olvida, cuando se olvida la mentira y su función vital con el fin de proyectar mundos donde habitan mayúsculas verdades, mundos en sí. El metafísico, lejos de hacer explícita esa proyección, la oculta, la olvida, necesita creer en la objetividad, necesita creer que el animal que miente es sólo un animal racional, discursivo, analítico, y es entonces cuando comienza a creer en $s u$ verdad.

La verdad es una construcción de códigos útiles, de ficciones necesarias para poder vivir, para poder convivir. Ésta es la función primaria de la verdad. Sin embargo, olvidamos que esta función de la verdad es una función para la vida, para nuestra vida. La filosofía se inserta en ese olvido y es así como llega a creer que el mundo se agota en la versión que más le gusta de una determinada concepción de las cosas y de la verdad misma. Para poder imponer esa versión que tomó por verdad absoluta, la filosofía supuso que el mundo se agota en nexos causales, vio en el mundo la realización del principio de razón suficiente, olvidó y quiso olvidar el carácter construido, ficcional de todo aquello que llama conocimiento, de todo aquello que detenta como verdad.

Pero, ¿de dónde viene ese olvido? Del poder mismo de la ficción, de la ilusión. Ese poder es tal, su utilidad es tan portentosa, que olvidamos todo lo que opera detrás de eso que consideramos verdad y conocimiento. Entonces comenzamos a fingir, a simular, a fijar parámetros, modelos que luego se irían convirtiendo en verdades pétreas, delimitamos fronteras entre lo que es verdad y lo que no lo es, imaginamos que existe una correspondencia entre el nombrar las cosas y las cosas mismas, creímos en una burda referencialidad del lenguaje, desconfiamos de la convención, olvidamos porque "solamente mediante el olvido puede el hombre alguna vez llegar a imaginarse que está en posesión de una 'verdad'” (Nietzsche, 2003: 21).

¿Y qué es entonces la verdad? ¿Cómo comienza Nietzsche a entenderla a la vez que critica los supuestos de la metafísica? Conocemos bien la respuesta de Nietzsche a esta pregunta, o al menos una de sus respuestas: “¿Qué es entonces la verdad? Una hueste en movimiento de metáforas, metonimias, antropomorfismos, en resumidas cuentas, una suma de relaciones humanas que han sido realzadas, extrapoladas y adornadas poética y retóricamente y que, después de un prolongado uso, un pueblo considera 
firmes, canónicas y vinculantes; las verdades son ilusiones de las que se ha olvidado que lo son; metáforas que se han vuelto gastadas y sin fuerza sensible, monedas que han perdido su troquelado y no son ahora ya consideradas como monedas, sino como metal" (1994: 25).

¿Qué quiere decir esto? Que todo concepto pretendidamente inamovible no fue en su génesis otra cosa que una metáfora, una inocente mentira, un deseo de vida. Vida y ficción están íntimamente ligadas. La idea de ficción en Nietzsche tiene en un primer momento una significación básicamente vital, como ya se ha mencionado; es una necesidad, un impulso que tiene por resultado una utilidad: "en algún apartado rincón del universo centelleante [...] hubo una vez un astro en el que animales centelleantes inventaron el conocimiento" (1994: 17). Aquí, la verdad y el conocimiento no son sino ficciones que a su vez son un medio para vivir, un medio que luego olvidamos y al que le dimos una dimensión sacrosanta. Fue entonces que nos separamos de las palabras, del lenguaje, que les dimos existencia objetiva. Construimos otra realidad, la del concepto, la de las cadenas causales, la del principio de razón suficiente. Pero no sólo eso. Además, señala Nietzsche, depositamos en esto un valor, valoramos aquellas operaciones y comenzamos a creer que el mundo del concepto era más válido frente a la movilidad y gratuidad de nuestro mundo, que mediante el concepto quedaría regulado, sometido. Sin esta regulación resultaría falso. Aprendimos a confiar en el concepto, a sustituir la vida por éste. Así, la metaforicidad primera que constituye nuestra acción sobre el mundo, se desgastó, se petrificó. Es en este sentido que la filosofía de corte racionalista partió del "error de creer que tiene cosas ante sí de manera inmediata, como objetos puros. Por tanto, olvida que las metáforas intuitivas originales no son más que metáforas y las toma por las cosas mismas" (1994: 29).

Pero, si la primera formación de las palabras obedece a impulsos, Nietzsche se pregunta, ¿qué nos autorizó a creer que ellas designan objetivamente cosas más allá de nosotros? La arbitrariedad. Hablamos de las cosas y al hacerlo creemos saberlas, inventamos la idea de la posibilidad de conocer las cosas en su "esencia". "El pensamiento sería imposible si no tuviera, fundamentalmente, una 'concepción' errónea de la naturaleza del ser: debe predicar sustancia e igualdad [...] debe adscribir atributos a la 'realidad', para existir él mismo" (Vaihinger: 61).

$\mathrm{Al}$ ahondar en el vínculo entre el lenguaje y la verdad, Nietzsche señala que ni la verdad, ni el conocimiento, ni el lenguaje mismo surgen de la base de un pensamiento lógico. Lejos de ello, surgen de la más inmediata potencia creadora que caracteriza a la humana existencia: crear metáforas, simbolizar, significar, narrar significadamente la realidad, la realidad que no es nunca sino nuestra realidad. Asumir esto no causaría al metafísico sino horror: toda la gloriosa ciencia, todo el inmaculado conocimiento se alza sobre una base que no obedece a ninguna lógica. Por eso, el metafísico prefiere creer que nuestra originaria actitud estética, poiética, es una actitud lógica. Niega que lo que hacemos es crear mediaciones, inventar relaciones con las cuales damos un rostro más seguro a nuestro inseguro mundo. A la creación de sentidos le dio el nombre y la categoría de leyes de la naturaleza. El ente creador se miró a sí mismo, con 
la filosofía, como sujeto de conocimiento. Y - he aquí otro olvido- puso en esas leyes lo que ahí quería encontrar.

Al parecer, hemos creído que el mundo es más confiable en la medida en que olvidamos que nosotros mismos lo creamos al significarlo. Esto quiere decir que desconfiamos de nuestra más significativa potencia: nuestra potencia creadora. Con esta desconfianza llegan otras desconfianzas: hacia la vida, hacia el mundo y su carácter siempre deviniente y contradictorio. El mundo del ser, de la unidad, de la identidad, nos devolvía la confianza. Se podía hacer de lo irregular algo regular, de lo inapresable algo apresable: mundo verdadero y mundo aparente, el primero es el de la razón y la ciencia, el segundo, el del arte y todos aquellos órdenes del saber a los que la filosofía negó condición de verdad, aquellos que excluyó del reino del conocimiento. Pero el arte nunca pareció olvidar su carácter de ilusión, no olvidó que la vida necesita de la ilusión, que es necesario confiar en la ilusión lejos de olvidarla.

El mundo humano es un mundo de despliegue de sentidos. Nosotros hacemos que las cosas tengan sentido y no a la inversa. Tal vez uno de los motivos por los que no queremos ver en el conocimiento y la verdad su dimensión ficcional es porque toda ficción, como señala Nietzsche, supone una perspectiva de la vida. Más aún: la perspectiva es la condición fundamental de toda vida. Nos horroriza aceptar la perspectiva porque ésta nos muestra el carácter relativo, histórico, efímero y finito de todo lo que detentamos como verdad absoluta y conocimiento objetivo. Nos horroriza pensar que no tenemos más que perspectivas, es decir, interpretaciones del mundo, interpretaciones en las que la vida se sustenta.

La filosofía, sobre todo en su acepción racionalista, busca tornar todo en algo pensable, conceptualizable, esquematizable, obliga a la realidad a comparecer frente al concepto y se opone al cambio, en el que sólo ve dolor y angustia, azar, sorpresa, imprevisibilidad. Por esto, la filosofía estuvo dispuesta a despreciar los sentidos, el devenir, a enviar toda esta dimensión de la vida a ese oscuro recinto donde yace lo no verdadero, donde habita la pluralidad y la diversidad, el cuerpo y la finitud, los instintos y la contradicción. Al otro lado de esta dimensión, en un mundo luminoso, le dio residencia a la razón, a la verdad que homogeneiza. Ésta es para Nietzsche la operación básica de toda concepción metafísica de la verdad: momificar, organizar, estabilizar, darle nombre a esa estabilidad (Dios, sujeto, razón, sustancia, conciencia, etcétera) (Nietzsche, 1997). Y no sólo eso, la concepción metafísica de la verdad también tasa la vida desde el conocimiento. Así, metafísica y moral sellan con solidez matemática sus irrompibles lazos: verdad = moral, mentira $=$ inmoral. Gracias a estas operaciones, todo lo que escapa a los límites de la razón discursiva fue condenado y la razón quedó fuera del mundo, de la historia, más allá de toda circunstancia, de todo azar, de toda perspectiva.

No obstante, para Nietzsche la voluntad de ilusión es más profunda que la voluntad de verdad. La genealogía sería la encargada de denunciar los delirios de la racionalidad y de revelar que la historicidad y la temporalidad penetran toda pretensión de verdad y de conocimiento. Pero el pensamiento nietzscheano no se limitaría a la 
denuncia, no sin antes construir una concepción del lenguaje, pues, a fin de cuentas, la verdad para Nietzsche no es sino un evento del lenguaje, lo mismo que las distintas visiones, las perspectivas sobre el mundo. Para Nietzsche, nos dice Luis Enrique de Santiago, "la verdad es una función del lenguaje. Esta idea [...] anticipa las tesis fundamentales del siglo XX" (349). Pensar el problema de la verdad en Nietzsche implica pensar la manera en que éste concibió el lenguaje, pues "uno de los aspectos más importantes del pensamiento de Nietzsche, sin el cual su filosofía perdería toda esa tensión creativa que genera, es su reflexión radical sobre el lenguaje y la perspectiva estética desde la que lo piensa. Para comprender [...] su crítica a los problemas tradicionales de la metafísica y la epistemología, es imprescindible contar con esa guía hermenéutica o 'hilo conductor', que es el lenguaje" (349).

Al introducir el problema de la verdad en el terreno del lenguaje, lo que Nietzsche hace, como sabemos, es poner en crisis esa razón y esa conciencia que creía estar en posesión total de sí misma y de lo real; hacer temblar esa dimensión de la razón que se pretendió única, objetiva, ordenadora, excluyente, aquella que creía resolver todos los abismos y contradicciones, aquella que vio en el lenguaje no una manifestación de la vida, sino la posibilidad de ejecutar sobre ella la unidad, de fijar la definición que pudiese atraparla, esclarecerla. La razón vio hechos ahí donde hay lenguaje y significación, vio realidades dadas ahí donde el lenguaje configura mundos, vio objetos evidentes ahí donde se desgastaron las metáforas y los sentidos. La conciencia creyó interpretar las cosas desde ellas mismas y no desde los horizontes de sentido que posibilitan toda interpretación, toda concepción incluso de las cosas. La metafísica supuso que el lenguaje podía hacer del mundo algo estable, negó el carácter ya siempre metafórico del mismo, se pensó que con el lenguaje, como señala Conill, ${ }^{6}$ podíamos reproducir algo como "la realidad en sí" (Conill, 1997).

Para Nietzsche, el lenguaje es él mismo perspectiva, como lo es o lo son las verdades. La metafísica considera esto una pérdida, como si asumirlo implicara renunciar al saber, al conocer. Nietzsche, por el contrario, ubica en la perspectiva una ganancia: cada valor depende de un punto de vista, de una manera de darse la voluntad de poder. En este sentido, no hay perspectivas verdaderas o falsas. Esto no implica la tan temida arbitrariedad, o el horrorizante relativismo del que tanto ha parecido rehuir la metafísica. No todo vale por igual: hay distancia y diferencia entre las perspectivas, diversos parámetros de su validez, como lo sería, por ejemplo, la óptica de la vida para Nietzsche.

La afirmación del carácter de interpretación y perspectiva de toda verdad tiene en Nietzsche un sentido ontológico. Es decir, la perspectiva no sólo es el modo de ser del lenguaje, sino que expresa el modo de ser del ser humano: apertura de sentidos y significados, visiones del mundo. En tanto que somos lenguaje, como lenguaje y, por lo tanto, como significación, se da la apertura humana del mundo. Para la metafísica, el lenguaje no es más que un medio para captar la realidad "real". Para Nietzsche, el

\footnotetext{
${ }^{6}$ Este texto resulta fundamental para entender las tesis nietzscheanas en torno al lenguaje y la verdad.
} 
lenguaje es muestra de que la objetividad es una ingenuidad, una búsqueda ingenua. El lenguaje nos abre significadamente al mundo, el lenguaje mismo es concepción del mundo, concepciones del mundo.

De esta manera, la verdad no es adecuación con ningún ser en sí, con ningún hecho, sino un fenómeno de la voluntad de poder en tanto ésta se da como interpretación del mundo, de lo que somos y de lo que el mundo es para nosotros: un evento de significación, de interpretación. Con esto, lo que Nietzsche quiso abandonar, "fue la determinación lógico-metafísica de la verdad" y la consecuente idea de que el lenguaje está ahí para dominar y controlar la realidad y la verdad. Lo que Nietzsche descubrió así fue "que los diversos conceptos fundamentales de la metafísica a los que está ligado el concepto de la verdad [...] son producción de una falsa "cosificación"” (Nietzsche, 1997: 65).

Si pensamos en las primeras reflexiones de Nietzsche sobre el lenguaje, vinculadas, como es obvio, con el tema de la verdad, nos daremos cuenta, como apunta De Santiago, que Nietzsche ubica el lenguaje en un nivel primario relacionado con instintos creadores. En este nivel, el lenguaje no es efecto de una conciencia discursiva que pretende ordenar el mundo sino impulso (De Santiago: 352 y ss). Y es este impulso del lenguaje el que hace mundo, el que lo constituye como sentido y significación, el que lo interpreta. La verdad es pathos.

Al ubicar la verdad en el terreno del lenguaje y, por tanto, de la interpretación y la perspectiva, lo que Nietzsche reclama es la necesidad de construir una racionalidad cruzada por la historicidad y la finitud, una concepción de la vida como donación de sentido. Para Nietzsche, sin perspectiva no hay conocimiento ni verdad, no hay concepciones del mundo sin el horizonte de significado que las posibilita. En dicho horizonte opera el poder de la historicidad, de la tradición, que no podemos rebasar en tanto nos constituyen. Cada perspectiva es una posición sobre el mundo, una manera de valorarlo. La perspectiva es por sí misma una valoración que se inscribe siempre en horizontes de sentido, en horizontes históricos. Es en este punto donde las concepciones nietzscheanas del lenguaje y de la verdad se tornan hermenéuticas o anticipan su hermeneutización, que, como señalábamos antes, va de la mano con la genealogía (Rivara, 2004). La labor crítica del genealogista implica la conciencia de moverse en horizontes de sentido que, a su vez, impulsan su crítica y su interpretación. El genealogista nunca accede a ninguna verdad porque él pone en evidencia la dimensión perspectivística de toda interpretación, su carácter lingüístico y, con ello, reconoce la imposibilidad de fijar interpretaciones, de darlas por definitivas y cerradas.

Al incorporar Nietzsche la conciencia de la perspectiva en la interpretación, modifica el sentido de la palabra "verdad". Después de Nietzsche, puede decirse que cualquier pretendido desinterés u objetividad omite un dato inherente a toda interpretación: que ésta no carece de supuestos previos. Nietzsche señalaba que es necesario exponer no tanto los supuestos, sino el hecho de su existencia y la forma en que operan en toda interpretación, dirigiéndola incluso. Esto sería algo así como dar testimonio de la conciencia hermenéutica, señalar la necesidad de explicitarla. Para lograrlo es 
indispensable ese paso crítico que se torna un momento de toda interpretación. Podríamos decir que se trata de algo así como la exposición de la situación hermenéutica, los prejuicios y la tradición, por usar los términos de Gadamer. La verdad adquiere así un carácter histórico y se ubica justamente como otro elemento más de los horizontes de sentido, de los cuales, dicho otra vez con Gadamer, tampoco podemos salir arbitrariamente, pues constituyen la realidad de nuestro ser. Ya para el propio Nietzsche, la exposición de los supuestos no se realizaba desde una posición neutral, pura, sino, a su vez, desde una óptica y un horizonte. Como sabemos ahora con Gadamer, ese horizonte no es fijo ni aislable, y de ese horizonte no podemos desprendernos: no es objeto.

La verdad, las verdades, así, quedan vinculadas más bien con cadenas argumentativas, con aconteceres de sentido y no con objetos evidentes ni con realidades dadas. No hay adecuación. La verdad queda puesta en relación con los intereses, juicios, prejuicios y tradiciones expuestos en toda visión del mundo. Al ser un fenómeno que tiene que ver con prácticas concretas, con aconteceres históricos de sentidos, con validaciones de ópticas de la vida, la verdad nunca puede ser la certeza de un sujeto frente a un objeto. En este sentido, la perspectiva no reduce la comprensión, sino que la potencia y ensancha, pues desvela la dependencia de toda interpretación respecto de un sistema de ópticas, de creencias, de juicios; desvela su dependencia de la voluntad, que crea visiones del mundo, visiones que, en última instancia, no se distinguen por tener unas más verdad que otras, sino por ser su validez subsidiaria de la propia tradición. Por mencionar de nuevo a Gadamer, el límite de la interpretación, en todo caso, lo constituye la propia tradición. Esto es así porque la perspectiva no es una posesión o propiedad ni de un fenómeno, ni de un texto, ni de un intérprete, sino la manera misma en que se abre la experiencia humana del mundo: como lenguaje, como historicidad.

En resumen, la problematización que hace Nietzsche de la noción de verdad a partir de los elementos que hemos señalado no implica ninguna visión arbitraria de la verdad. La impronta del perspectivismo no anula la validez de una interpretación por encima de otras. Nunca para Nietzsche toda interpretación vale por igual. Para nuestro autor existen, en efecto, límites en las interpretaciones, y esos límites tienen que ver con las ópticas que las validan, con sus posibilidades de potenciar o no la vida, de afirmarla o negarla, "porque toda ilusión sólo puede dar uno de dos resultados posibles: o engrandece la vida, o la deprime. Una ilusión que engrandece la vida, lo hace porque la cimienta en sus instintos y confía en ellos, y por lo mismo la vida fluye, se torna creativa" (Rivero: 107). ${ }^{7}$

Con todo esto, señalo que Nietzsche captó una de las grandes improntas filosóficas de su siglo y también del siglo que vendría: hacer emerger el tema de la vida como el tema básico y fundamental sobre el cual podrían tratarse, entonces, los grandes temas

\footnotetext{
${ }^{7}$ En este texto la autora analiza a profundidad el tema de la verdad en Nietzsche desde la perspectiva de El nacimiento de la tragedia, en donde la verdad y su problematización está indefectiblemente vinculada al gran tema nietzscheano del arte.
} 
del conocimiento, entre ellos, el problema de la verdad. Nietzsche ya había detectado - y ello forma parte de su herencia, que hoy sigue dando frutos - que no hay forma de aproximarnos a la verdad y al conocimiento sin aproximarnos a sus fuentes primigenias, básicas, fundamentales: la vida, la historicidad del ser, la temporalidad de la conciencia y, sin duda, esa huella, esa impronta radical en la que se da la apertura humana del mundo, el lenguaje.

El siglo XX filosófico ha sido, mucho más de lo que a veces ha podido o querido darse cuenta, nietzscheano; ha bebido de los frutos de la obra de Nietzsche, se ha nutrido de sus manantiales mucho más de lo que en ocasiones reconoce.

\section{Obras citadas}

ConiLl, Jesús. 1997. El poder de la mentira. Nietzsche y la política de la transvaloración. Madrid: Tecnos.

De Santiago, Luis Enrique. 2004. Arte y poder: aproximación a la estética de Nietzsche. Madrid: Trotta.

NiETZSCHE, Friedrich. 2003. "Sobre el pathos de la verdad", Dios ha muerto. Trad. María Antonia GonzÁlez VAlERIO. México: UNAM.

1997. Crepúsculo de los ídolos. Ed. Andrés SÁnchez PASCUAL. Madrid: Alianza.

1994. Sobre verdad y mentira en sentido extramoral. Trad. Luis M. VALDÉS

y Teresa ORDuÑA. Madrid: Tecnos.

RIVARA, Greta. 2004. "Nietzsche: una cuestión hermenéutica”. Entre hermenéuticas. Coord. y ed. María Antonia GonzÁlez, Greta Rivara y Paulina Rivero. México: UNAM.

Rivero, Paulina. 2004. Nietzsche: verdad e ilusión. México: unAM/Ítaca.

VAIHINGER, Hans. 1994. "La voluntad de ilusión en Nietzsche”. Sobre verdad y mentira. Madrid: Tecnos. 